attack rate from children to household members was estimated to be only $0.5 \%$ (7). Reduced transmission from children in households was also reported in Switzerland and China and in educational settings in Australia (8-10).

This study is limited by its small sample size, which limits the ability to generalize its results. Moreover, we did not assess the patients' viral load, which could indirectly reflect the infectivity of the children, nor did we assess patient serology, which could further ascertain their infection status. Despite these limitations, our study provides information on SARSCoV-2 transmission from children to guardians in isolation rooms. Additional assessments of the transmissibility of SARS-CoV-2 by children and the role of PPE in preventing infection could provide guidance during the ongoing pandemic. Nonetheless, our study adds to growing evidence that young children are less likely to contribute to the spread of COVID-19 among their adult guardians.

\section{About the Author}

Dr. E.J. Lee is a pediatrician at the Seongnam Citizens Medical Center, Seongnam, Korea. Her clinical expertise is in the field of pediatric gastroenterology, and her primary research focuses on gut microbiome in children.

\section{References}

1. Han MS, Choi EH, Chang SH, Jin B-L, Lee EJ, Kim BN, et al. Clinical characteristics and viral RNA detection in children with COVID-19 in the Republic of Korea. JAMA Pediatr. 2020 Aug 28 [Epub ahead of print]. https://doi.org/10.1001/ jamapediatrics.2020.3988

2. Furukawa NW, Brooks JT, Sobel J. Evidence supporting transmission of severe acute respiratory syndrome coronavirus 2 while presymptomatic or asymptomatic. Emerg Infect Dis. 2020 May 4 [Epub ahead of print]. https://doi.org/10.3201/eid2607.201595

3. Leung NHL, Chu DKW, Shiu EYC, Chan KH, McDevitt JJ, Hau BJP, et al. Respiratory virus shedding in exhaled breath and efficacy of face masks. Nat Med. 2020;26:676-80. https://doi.org/10.1038/s41591-020-0843-2

4. Chu DK, Akl EA, Duda S, Solo K, Yaacoub S, Schünemann HJ, et al.; COVID-19 Systematic Urgent Review Group Effort (SURGE) study authors. Physical distancing, face masks, and eye protection to prevent person-to-person transmission of SARS-CoV-2 and COVID-19: a systematic review and meta-analysis. Lancet. 2020;395:1973-87. https://doi.org/10.1016/S0140-6736(20)31142-9

5. Lee B, Raszka WV Jr. COVID-19 transmission and children: the child is not to blame. Pediatrics. 2020;146:e2020004879. https://doi.org/10.1542/ peds.2020-004879

6. Park YJ, Choe YJ, Park O, Park SY, Kim YM, Kim J, et al.; COVID-19 National Emergency Response Center, Epidemiology and Case Management Team. Contact tracing during coronavirus disease outbreak, South Korea, 2020. Emerg Infect Dis. 2020;26:2465-8. https:/ / doi.org/10.3201/ eid2610.201315
7. Kim J, Choe YJ, Lee J, Park YJ, Park O, Han MS, et al. Role of children in household transmission of COVID-19. Arch Dis Child. 2020 [Epub ahead of print]. https:/ / doi.org/10.1136/ archdischild-2020-319910

8. Posfay-Barbe KM, Wagner N, Gauthey M, Moussaoui D, Loevy N, Diana A, et al. COVID-19 in children and the dynamics of infection in families. Pediatrics. 2020;146:e20201576. https:// doi.org/10.1542/peds.2020-1576

9. Jiehao C, Jin X, Daojiong L, Zhi Y, Lei X, Zhenghai Q, et al. A case series of children with 2019 novel coronavirus infection: clinical and epidemiological features. Clin Infect Dis. 2020;71:1547-51. https://doi.org/10.1093/cid/ciaa198

10. Macartney K, Quinn HE, Pillsbury AJ, Koirala A, Deng L, Winkler N, et al.; NSW COVID-19 Schools Study Team. Transmission of SARS-CoV-2 in Australian educational settings: a prospective cohort study. Lancet Child Adolesc Health. 2020;4:807-16. https:// doi.org/10.1016/ S2352-4642(20)30251-0

Address for correspondence: Mi Seon Han, Department of Pediatrics, Seoul Metropolitan Government-Seoul National University Boramae Medical Center, 20 Boramae-ro 5-gil, Dongjak-gu, Seoul 07061, South Korea; email: msh0827@snu.ac.kr

\section{Superspreading Event of SARS-CoV-2 Infection at a Bar, Ho Chi Minh City, Vietnam}

Nguyen Van Vinh Chau, Nguyen Thi Thu Hong, Nghiem My Ngoc, Tran Tan Thanh, Phan Nguyen Quoc Khanh, Lam Anh Nguyet, Le Nguyen Truc Nhu, Nguyen Thi Han Ny, Dinh Nguyen Huy Man, Vu Thi Ty Hang, Nguyen Thanh Phong, Nguyen Thi Hong Que, Pham Thi Tuyen, Tran Nguyen Hoang Tu, Tran Tinh Hien, Ngo Ngoc Quang Minh, Le Manh Hung, Nguyen Thanh Truong, Lam Minh Yen, H. Rogier van Doorn, Nguyen Thanh Dung, Guy Thwaites, Nguyen Tri Dung, Le Van Tan, for the OUCRU COVID-19 research group ${ }^{1}$

\footnotetext{
${ }^{1}$ Members of the group are listed in the Appendix (https://wwwnc. cdc.gov/EID/article/27/1/20-3480-App1.pdf).
} 
Author affiliations: Hospital for Tropical Diseases, Ho Chi Minh City, Vietnam (N.V.V. Chau, N.M. Ngoc, D.N.H. Man, N.T. Phong, N.T.H. Que, P.T. Tuyen, T.N.H. Tu, L.M. Hung, N.T. Truong, N.T. Dung); Oxford University Clinical Research Unit, Ho Chi Minh City (N.T.T. Hong, T.T. Thanh, P.N.Q. Khanh, L.A. Nguyet, L.N.T. Nhu, N.T.H. Ny, V.T.T. Hang, T.T. Hien, L.M. Yen, H.R. van Doorn, G. Thwaites, L.V. Tan); Children's Hospital 1, Ho Chi Minh City (N.N.Q. Minh); Centre for Tropical Medicine and Global Health, Oxford, UK (H.R. van Doorn, G. Thwaites); Ho Chi Minh City Centre for Disease Control and Prevention Ho Chi Minh City (N.T. Dung)

DOI: https://doi.org/10.3201/eid2701.203480

We report a superspreading event of severe acute respiratory syndrome coronavirus 2 infection initiated at a bar in Vietnam with evidence of symptomatic and asymptomatic transmission, based on ministry of health reports, patient interviews, and whole-genome sequence analysis. Crowds in enclosed indoor settings with poor ventilation may be considered at high risk for transmission.

Superspreading events occur when a few persons Sinfect a larger number of secondary persons with whom they have contact $(1,2)$. For severe acute respiratory syndrome coronavirus 2 (SARS-CoV-2), an $\mathrm{R}_{0}$ of 2-3 with 6-8 secondary cases has been suggested to constitute a superspreading event (3).

Although SARS-CoV-2 is known to be transmitted through droplets and fomites, there has been growing evidence of airborne transmission $(4,5)$. Better understanding of specific settings in which superspreading events are facilitated remains critical to inform the development and implementation of control measures to avoid future waves of the pandemic (5).

On March 18, 2020, a 43-year old man, patient 1, sought treatment at the Hospital for Tropical Diseases in Ho Chi Minh City, Vietnam, for fever, cough, muscle aches, fatigue, and headache. A sample from a nasopharyngeal throat swab specimen taken at admission tested positive for SARS-CoV-2 by reverse transcription PCR.

During the 14 days before the onset of his symptoms on March 17, he had traveled to Thailand and within Vietnam, between Hanoi and Ho Chi Minh City. From 10:00 PM on March 14 until 2:30 AM of the next day, he participated in a St. Patrick's Day celebration at bar X in Ho Chi Minh City. The bar had 2 indoor areas for clients, an $\approx 300-\mathrm{m}^{2}$ area downstairs and an $\approx 50-\mathrm{m}^{2}$ area upstairs, with no mechanical ventilation. During open hours, the left and right entrances were typically kept closed to facilitate cooling with air conditioners that recycle indoor air; the middle entrance was kept open. The bar also has naturally ventilated outdoor spaces (Appendix, https:/ / wwwnc.cdc.gov/EID/article/27/1/203480-App1.pdf). Patient 1 was inside the bar during the party.

After the confirmed diagnosis of COVID-19 in patient 1 , we used contact tracing and testing to

\begin{tabular}{|c|c|c|c|c|c|c|}
\hline $\begin{array}{l}\text { Patient } \\
\text { no. }\end{array}$ & Contact history and epidemiologic factors & $\begin{array}{l}\text { Inside } \\
\text { bar? }\end{array}$ & $\begin{array}{c}\text { Travel } \\
\text { history† }\end{array}$ & Occupation & $\begin{array}{c}\text { Symptom } \\
\text { onset }\end{array}$ & Diagnosed \\
\hline \multicolumn{7}{|c|}{ Patients present at bar X for celebration on March 14-15, 2020} \\
\hline 1 & Attended with patients 2,3 , and 4 & $\mathrm{Y}$ & $\mathrm{Y}$ & Pilot & $03 / 17$ & Mar 18 \\
\hline 2 & Attended with patients 1,3 , and 4 ; roommate of patient 3 & UNK & $\mathrm{Y}$ & Teacher & Unavail.‡ & Mar 22 \\
\hline 3 & Attended with patients 1,2 , and 4 ; roommate of patient 2 & UNK & $\mathrm{Y}$ & Teacher & Unavail. & Mar 22 \\
\hline 4 & Attended with patients 1,2 , and 3 & UNK & $\mathrm{N}$ & Teacher & Mar 21 & Mar 22 \\
\hline 5 & Attendee; works at shoe company $Y$ & UNK & $\mathrm{N}$ & Unavail. & Asympt. & Mar 23 \\
\hline 6 & Waiter at bar X; in close contact with patient 1 & $\mathrm{Y}$ & $\mathrm{N}$ & Bar X waiter & Mar 16 & Mar 23 \\
\hline 7 & Attendee & UNK & $\mathrm{N}$ & Unavail. & Unavail. & Mar 24 \\
\hline 8 & Attendee; friend of patient 7 & UNK & $\mathrm{N}$ & Teacher & Unavail. & Mar 24 \\
\hline 9 & Attendee & UNK & $\mathrm{N}$ & Teacher & Mar 25 & Mar 26 \\
\hline 10 & Attendee & UNK & $\mathrm{N}$ & Technician & Asympt. & Mar 26 \\
\hline 11 & Attended with patient 5 & UNK & $\mathrm{N}$ & Unavail. & Unavail. & Mar 28 \\
\hline 12 & Attendee & UNK & $\mathrm{N}$ & Unavail. & Asympt. & 04/02 \\
\hline 13 & Attended with patient 12 & UNK & $\mathrm{N}$ & Unavail. & Mar 26 & $04 / 03$ \\
\hline \multicolumn{7}{|c|}{ Contacts of patients present at bar X for celebration on March 14-15, 2020} \\
\hline 14 & Contact of patients 5 and 19 as coworkers at shoe company $Y$ & NA & $\mathrm{N}$ & Unavail. & Asympt. & Mar 25 \\
\hline 15 & Household contact of patient 10 & NA & $\mathrm{N}$ & Unavail. & Asympt. & Apr 1 \\
\hline 16 & Household contact of patient 6 & NA & $\mathrm{N}$ & Unavail. & Unavail. & Mar 27 \\
\hline 17 & Contact (driver) of patients 5 and 14 & NA & $\mathrm{N}$ & Driver & Mar 27 & Mar 30 \\
\hline 18 & $\begin{array}{l}\text { Household contact of patient } 14 \text {; also contact of patient } 5 \text { as a } \\
\text { coworker at shoe company } Y\end{array}$ & NA & $\mathrm{N}$ & Unavail. & Asympt. & Mar 30 \\
\hline 19 & Contact of patients 5 and 14 as coworkers at shoe company $Y$ & NA & $\mathrm{N}$ & Unavail. & Unavail. & Apr 6 \\
\hline
\end{tabular}

*Asympt., asymptomatic; NA, Not applicable; unavail., unavailable; UNK, unknown.

†Traveled to an area with known local transmission in previous $14 \mathrm{~d}$.

łBecause patient did not enroll in the clinical study, but asymptomatic at time of diagnosis. 
detect 18 additional PCR-confirmed cases. Of these, 12 (patients 2-13) were at bar X during the evening of March 14; the other 6 (patients 14-19) were contacts (Table; Appendix Figure). Of the patients with confirmed cases attending the celebration, 4 were in close contact with patient 1: patients $2-4$ went to the celebration with patient 1 and patient 6 worked as a waiter in the bar. Patients 2 and 3, who were roommates, had traveled to Malaysia and returned to Vietnam, patient 2 on March 13 and patient 3 on
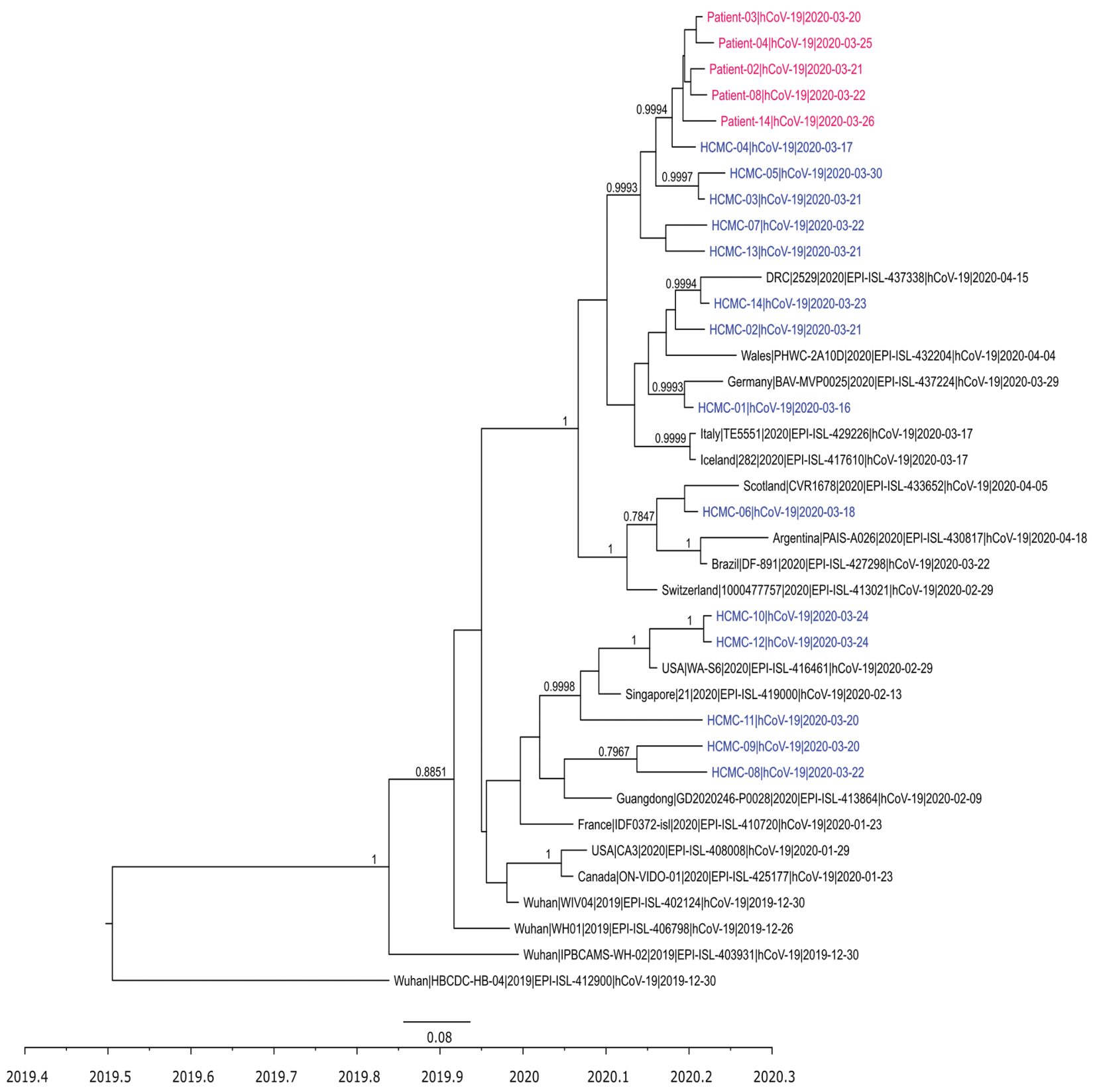

Figure. Time-scale phylogenetic tree illustrating the relatedness between whole-genome sequences of severe acute respiratory syndrome coronavirus 2 obtained from patients with confirmed cases of the cluster associated with a bar in Ho Chi Minh City, Vietnam, 2020, and reference sequences. Sequences from the cluster patients are in red; sequences from coronavirus disease patients in Ho Chi Minh City, not related to the cluster, are in blue. For those sequences, we obtained 21 genomes from the remaining 35 patients reported in Ho Chi Minh City as of April 24, 2020, for the purpose of the analysis; subsequently, we used 14 nonidentical sequences for the analysis. Representative sequences from patients not in Vietnam are in black. Posterior probabilities $\geq 75 \%$ are indicated at all nodes. The analysis was carried out using BEAST version 1.8.3 (https://beast.community). For time-scale analysis, only 1 representative of sequences that were $100 \%$ identical to each other was included. Whole-genome sequences were generated using ARTIC primers version 3 (ARTIC Network, https://artic.network/ncov-2019). 
March 6. The other patients, except for patient 1, had no recent history of travel outside of HCMC (Table).

By exploring the epidemiologic links discovered from in-depth interviews, we identified 3 possible transmission chains involving patients who attended the March 14 celebration (Table; Figure; Appendix Figure). Of these, 2 or 3 patients (patients 5, 10, and possibly 14) were asymptomatic but transmitted SARS-CoV-2 to their contacts (Table; Figure). None of the 19 patients with confirmed cases reported that they had respiratory signs or symptoms on March 14-15. However, in addition to patient 1 , a total of 5 others developed mild respiratory symptoms (patient 4 on March 16, patient 6 on March 21, patient 9 on March 25, patient 13 on March 26, and patient 17 on March 27), suggesting an incubation period of 2-12 days. Follow-up data were available for 12 patients who participated in our clinical study (Appendix). Six remained asymptomatic during follow-up (Appendix Table 1).

A total of 11 whole-genome sequences of SARSCoV-2 were obtained from the patients in the cluster. The obtained sequences were either $100 \%$ identical or different from each other by only 1-2 nt (Appendix Table 2). Phylogenetically, they clustered together tightly but were different from sequences obtained from other cases in Ho Chi Minh City during the same period.

As of September 15, 2020, only 30 cases of locally acquired infection had been reported in Ho Chi Minh City (6), but thiscluster represents theonly documented superspreading event $(6,7)$. Together with data from previous reports $(3,8,9)$, these data suggest that closed settings are facilitators of community transmission of SARS-CoV-2. The mechanism by which infected people without symptoms spread SARS-CoV-2 to others, especially in closed settings, warrants further research, including on transmission through aerosols, which has been suggested $(4,10)$.

The high level of genome sequence similarity between the SARS-CoV-2 genomes obtained from the patients and the tight clustering on the phylogenetic tree strengthen the epidemiologic link between the PCR-confirmed cases from this cluster. Together with contact history, these data also support transmission chains involving asymptomatic carriers (patients 5 and 14) as the sources of the ongoing infection. However, the identity of the patient in the index case from the bar could not be confirmed, in part because in-depth interview data were available from only 8 of 13 patients with confirmed cases who consented to participate in the study. In conclusion, our results emphasize that persons in crowded indoor settings with poor ventilation may be considered to be at high risk for SARS-CoV-2 transmission.

\section{Acknowledgments}

We are indebted to Nguyen Thanh Ngoc, Le Kim Thanh, and the OUCRU IT/CTU/Lab management departments, especially Ho Van Hien, Dang Minh Hoang, and Nguyen Than Ha Quyen, for their support. We thank Maia Rabaa at OUCRU for her initial discussion about the analysis, and Leigh Jones at OUCRU for her input with some of the epidemiological data. Finally, we thank the patients for their participation in this study and the doctors and nurses of the Hospital for Tropical Diseases, who cared for the patients and provided the logistic support with the study.

This study was funded by the Wellcome Trust of Great Britain (106680/B/14/Z and 204904/Z/16/Z).

\section{About the Author}

Dr. Chau is the director of the Hospital for Tropical Diseases in Ho Chi Minh City, Vietnam. He is a frontline healthcare worker in the COVID-19 pandemic.

\section{References}

1. Wang SX, Li YM, Sun BC, Zhang SW, Zhao WH, Wei MT, et al. The SARS outbreak in a general hospital in Tianjin, China - the case of super-spreader. Epidemiol Infect. 2006;134:786-91. https://doi.org/10.1017/ S095026880500556X

2. Cho SY, Kang J-M, Ha YE, Park GE, Lee JY, Ko J-H, et al. MERS-CoV outbreak following a single patient exposure in an emergency room in South Korea: an epidemiological outbreak study. Lancet. 2016;388:994-1001. https:/ /doi.org/ 10.1016/S0140-6736(16)30623-7

3. Adam DC, Wu P, Wong JY, Lau EHY, Tsang TK, Cauchemez $\mathrm{S}$, et al. Clustering and superspreading potential of SARS-CoV-2 infections in Hong Kong. Nat Med. 2020 Sep 17 [Epub ahead of print].

4. Morawska L, Milton DK. It is time to address airborne transmission of COVID-19. Clin Infect Dis. 2020;ciaa939. https://doi.org/10.1093/cid/ciaa939

5. World Health Organization. Transmission of SARS-CoV-2: implications for infection prevention precautions. 2020. [cited on 2020 Jul 24] https:/ / www.who.int/news-room/ commentaries/detail/transmission-of-sars-cov-2-implicationsfor-infection-prevention-precautions

6. Ministry of Health of Vietnam. Updated information about COVID-19 pandemic. Official page on acute respiratory infections COVID-19 [cited 2020 Sep 5]. http:/ / ncov.moh.gov.vn

7. Thanh HN, Van TN, Thu HNT, Van BN, Thanh BD, Thu HPT, et al. Outbreak investigation for COVID-19 in northern Vietnam. Lancet Infect Dis. 2020;20:535-6. https:/ / doi.org/10.1016/S1473-3099(20)30159-6

8. Pung R, Chiew CJ, Young BE, Chin S, Chen MIC, Clapham HE, et al.; Singapore 2019 Novel Coronavirus Outbreak Research Team. Investigation of three clusters of COVID-19 in Singapore: implications for surveillance and response measures. Lancet. 2020;395:1039-46. https:/ / doi.org/10.1016/S0140-6736(20)30528-6 
9. Ghinai I, Woods S, Ritger KA, McPherson TD, Black SR, Sparrow L, et al. Community Transmission of SARS-CoV-2 at Two Family Gatherings - Chicago, Illinois, FebruaryMarch 2020. MMWR Morb Mortal Wkly Rep. 2020;69:446-50. https:/ / doi.org/10.15585/mmwr.mm6915e1

10. Somsen GA, van Rijn C, Kooij S, Bem RA, Bonn D. Small droplet aerosols in poorly ventilated spaces and SARS-CoV-2 transmission. Lancet Respir Med. 2020;8:658-9. https://doi.org/10.1016/S2213-2600(20)30245-9

Address for correspondence: Le Van Tan, Oxford University Clinical Research Unit, Vo Van Kiet, District 5, Ho Chi Minh City, Vietnam; email: tanlv@oucru.org

\section{Racial and Workplace Disparities in Seroprevalence of SARS-CoV-2, Baton Rouge, Louisiana, USA}

\author{
Amy K. Feehan, Cruz Velasco, Daniel Fort, \\ Jeffrey H. Burton, Eboni G. Price-Haywood, \\ Peter T. Katzmarzyk, Julia Garcia-Diaz, \\ Leonardo Seoane
}

\begin{abstract}
Author affiliations: Ochsner Clinic Foundation, New Orleans, Louisiana, USA (A.K. Feehan, C. Velasco, D. Fort, J.H. Burton, E.G. Price-Haywood, J. Garcia-Diaz, L. Seoane); The University of Queensland Faculty of Medicine, Ochsner Clinical School, New Orleans (A.K. Feehan, E.G. Price-Haywood, J. Garcia-Diaz, L. Seoane); Pennington Louisiana State University, Baton Rouge, Louisiana, USA (P.T. Katzmarzyk); Louisiana State University Health Sciences Center-Shreveport, Shreveport, Louisiana, USA (L. Seoane)
\end{abstract}

\section{DOI: https://doi.org/10.3201/eid2701.203808}

By using paired molecular and antibody testing for severe acute respiratory syndrome coronavirus 2 infection, we determined point prevalence and seroprevalence in Louisiana, USA, during the second phase of reopening. Infections were highly variable by race and ethnicity, work environment, and ZIP code. Census-weighted seroprevalence was $3.6 \%$, and point prevalence was $3.0 \%$.

W e previously reported results from a seroprevalence study conducted in New Orleans, Louisiana, USA, which was hit hard early in the coronavirus disease (COVID-19) pandemic (1). Baton Rouge is a large metropolitan area roughly 80 miles northwest of New Orleans; at the time of this study, it was in the second phase of reopening after a stay-at-home order. Although the seroprevalence in New Orleans (6.9\%) (1) was similar to prevalence recorded in Spain (5\%), São Paulo, Brazil (4.7\%), and New York, USA (6.9\%) (2,3; B.H. Tess, unpub. data, https://doi.org/10.1101/20 20.06.29.20142331), Baton Rouge had only 3,427 more cases as of August 2, 2020 (17,093 cases), than New Orleans did by May 16, 2020 (13,666 cases) (4). This latest study estimated severe acute respiratory syndrome coronavirus 2 (SARS-CoV-2) infections in the greater Baton Rouge area (Ascension, East Baton Rouge, Livingston, and West Baton Rouge Parishes), with additional information on potential workplace exposures.

The protocol was approved by the Ochsner institutional review board and was designed to enroll and test $\leq 2,500$ participants at 13 sites throughout Baton Rouge during July 15-31. Recruitment targeted a representative sample by using a method developed by Public Democracy (https://www.publicdemocracy. io) and described elsewhere $(1,5)$. In contrast to the New Orleans study, in which persons tested were under a stay-at-home order, Baton Rouge was in phase 2 of reopening. A randomized subset of 500,000 Baton Rouge residents were targeted with digital ads for recruitment. Of those, 3,687 volunteers were recruited and restratified according to census designations; 2,309 were invited to participate, 2,179 enrolled and completed testing, and 2,138 were included in our final analysis. A total of 38 persons were excluded because they lived in ineligible ZIP codes, and 3 withdrew consent (Appendix Figure 1, https://wwwnc.cdc.gov/ EID/article/27/1/20-3808-App1.pdf). All study materials were provided in English, Spanish, and Vietnamese. Participants were offered free transportation. Research staff verbally obtained consent from participants and electronically documented consent and survey responses. We then procured blood samples and nasopharyngeal swab specimens from participants.

We used US Food and Drug Administration Emergency Use Authorization-approved tests. Realtime reverse transcription PCR of nasopharyngeal swab specimens was performed by using the Abbott m2000 RealTime system (Abbott, https:/ / www.molecular.abbott). Qualitative IgG blood tests were performed by using the ARCHITECT i2000SR (Abbott). The IgG test meets criteria established by the Centers for Disease Control and Prevention to yield high positive predictive value, which was validated by Ochsner Health laboratory and others $(6,7)$. Study participants who tested positive on either or both tests were 